\title{
Effects of Grape Seedlings Intercropping with Hyperaccumulators on Different Fractions of Cadmium Content in Soil
}

\author{
Kewen Huang ${ }^{1, a}$, Lijin Lin ${ }^{2, b}$ and Ming'an Liao ${ }^{1, c *}$ \\ ${ }^{1}$ College of Horticulture, Sichuan Agricultural University, Chengdu, Sichuan, China \\ ${ }^{2}$ Institute of Pomology and Olericulture, Sichuan Agricultural University, Chengdu, Sichuan, China \\ a263733029@qq.com, bllj800924@qq.com, Iman@sicau.edu.cn
}

${ }^{*}$ Corresponding author. Kewen Huang and Lijin Lin contributed equally to this work.

\section{Keywords: Intercropping; Hyperaccumulators; Cadmium fractions; Grape seedlings}

Abstract: In order to study the effects of grape seedlings intercropping with hyperaccumulators on five forms of cadmium in soil, a pot experiment was conducted to to study the effects of grape seedlings intercropping with Galinsoga parviflora, Siegesbeckia orientalis, Solanum nigrum and Crassocephalum crepidioides, respectively on exchangeable, bound to carbonates, bound to Fe-Mn oxides, bound to organic matter and residual cadmium contents. The results showed that compared with monoculture, only grape intercropping with $G$. parviflora could significantly increase the content of residual $\mathrm{Cd}$, which is conducive to the fixation of $\mathrm{Cd}$ in the soil and may reduce the plant's enrichment of $\mathrm{Cd}$. Therefore, grape seedlings intercropping with $G$. parviflora could benefit for the decline of bioavailability of $\mathrm{Cd}$.

\section{Introduction}

Cadmium $(\mathrm{Cd})$ is a harmful heavy metal element in the environment and is a dangerous environmental pollutant [1]. Studies have shown that the content of $\mathrm{Cd}$ in crops is not only related to the total $\mathrm{Cd}$ content of the soil, but also depends on the different chemical forms of $\mathrm{Cd}$ in the soil [2]. Cd in soil can be divided into five fractions: exchangeable, bound to carbonates, bound to Fe-Mn oxides, bound to organic matter and residual according to Tessier [3]. Exchange and residual $\mathrm{Cd}$ content directly determine the amount of $\mathrm{Cd}$ accumulation in plants. And the bioavailability of $\mathrm{Cd}$ bound to carbonates, $\mathrm{Cd}$ bound to $\mathrm{Fe}-\mathrm{Mn}$ oxides and $\mathrm{Cd}$ bound to organic matter are in dynamic equilibrium with the exchangeable state, and continuous supply source for exchangeable Cd [4]. Therefore, different forms of $\mathrm{Cd}$ in soil are the key factors to explore the $\mathrm{Cd}$ accumulation ability of plants. The study found that intercropping $\mathrm{Cd}$ hyperaccumulator with cash crop can effectively prevent and control the absorption of $\mathrm{Cd}$ by economic crop, which can be considered as an effective measure to improve food safety under Cd stress [5]. Grape (Vitis vinifera L.) is a worldwide fruit rich in vitamins, amino acids, minerals and glucose, which is a fruit that people love and eat for a long time, and is also used as medicine [6]. However, due to the serious pollution of $\mathrm{Cd}$ in orchards in recent years, it has affected the safe production of grape to some extent. Screening suitable hyperaccumulator to intercrop with grape may affect the $\mathrm{Cd}$ accumulation of grape by changing the form of $\mathrm{Cd}$ in the soil. In this study, four hyperaccumulators (Galinsoga parviflora [7], Siegesbeckia orientalis [8], Solanum nigrum [9] and Crassocephalum crepidioides [10]) were used to intercrop with grape seedlings under Cd stress, and the fractions of $\mathrm{Cd}$ in soil were measured. The aim of the study was to screen the best intercropping mode for reducing the bioavailability of Cd.

\section{Materials and Methods}

Materials collection. The seeds of four hyperaccumulators (G. parviflora, S. orientalis, S. nigrum, $C$. crepidioides) and the fluvo-aquic soil samples were collected from the farmland surrounding Chengdu Campus of Sichuan Agricultural University in April, 2016. The cultivar of grape is Kyoho with cutting seedlings. And the seeds of hyperaccumulators were sown in $25^{\circ} \mathrm{C}$ climate chamber in April, 2016. 
Experimental Design. The experiment was conducted in Chengdu Campus of Sichuan Agricultural University from April to July 2016. In April, the soil was air-dried, ground and passed through a 6.72-mm sieve. Each plastic pot $(21 \mathrm{~cm}$ high, $20 \mathrm{~cm}$ in diameter $)$ was filled with $3 \mathrm{~kg}$ of ground soil mixed with $5 \mathrm{mg} / \mathrm{kg} \mathrm{Cd}$ in solution (in the form of $\mathrm{CdCl}_{2} \cdot 2.5 \mathrm{H}_{2} \mathrm{O}$ ) for 4 weeks. In May 2016, three uniform seedlings (the shoots were about $15 \mathrm{~cm}$ ) of grape were transplanted into each pot for monoculture and two of them for intercropping, respectively. Then one uniform seedling of each hyperaccumulator with two pairs of true leaves was transplanted into each pot for intercropping. The experiment consists of 5 treatments: monoculture of grape, grape intercropping with $G$. parviflora, grape intercropping with $S$. orientalis, grape intercropping with $S$. nigrum and grape intercropping with $C$. crepidioides. Three replicates were run for each treatment, and the experiment pots were arranged in a completely randomized design. After 60 days, the soil from the rhizosphere in the corresponding pot was collected immediately when the plants were collected. All the soil samples were air-dried at room temperature then ground to pass through a 1-mm nylon sieve for analysis of five fractions of Cd. Soil samples $(1.0 \mathrm{~g})$ were digested with $5: 1(\mathrm{v}: \mathrm{v})$ $\mathrm{HNO}_{3}: \mathrm{HClO}_{4}$ and measured by novAA 400P flame atomic absorption spectrophotometer (Analytik Jena, Germany) [11].

Statistical Analyses. Statistical analyses were conducted using statistical software of SPSS 17.0. Data were analyzed by one-way ANOVA with least significant difference at 5\% confidence level.

\section{Results and Discussion}

The Content of Exchangeable Cadmium. For the content of exchangeable $\mathrm{Cd}$ in soil, compared to monoculture, only intercropping with $S$. orientalis significantly increased the content of exchangeable $\mathrm{Cd}$ in soil (Figure 1). Other treatments all had no significant effects on the content of exchangeable $\mathrm{Cd}(P>0.05)$.

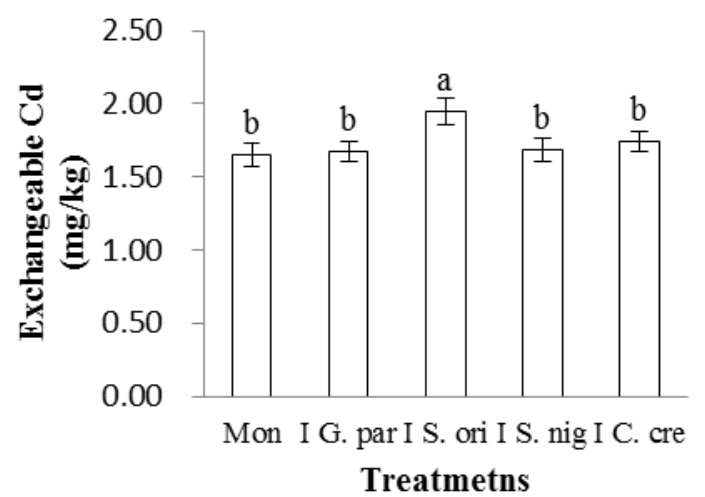

Fig. 1 The content of exchangeable $\mathrm{Cd}$ in soil. Different lowercase letters indicate significant differences based on one-way analysis of variance in SPSS 17.0 followed by the least significant difference test $(p<$ 0.05). $\mathrm{M}=$ monoculture, $\mathrm{I}$ G. par $=$ intercropping with $G$. parviflora, I S. ori $=$ intercropping with $S$. orientalis, I S. nig = intercropping with $S$. nigrum, I C. cre = intercropping with $C$. crepidioides.

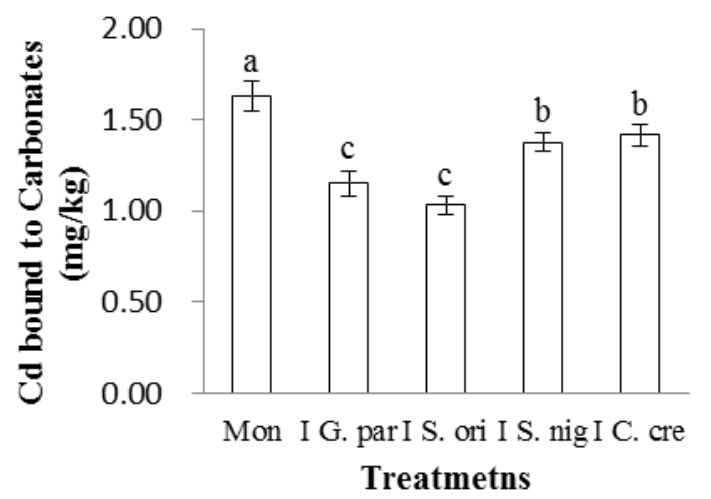

Fig. 2 The content of $\mathrm{Cd}$ bound to carbonates in soil. Different lowercase letters indicate significant differences based on one-way analysis of variance in SPSS 17.0 followed by the least significant difference test $(p<$ 0.05). $\mathrm{M}=$ monoculture, I G. par = intercropping with $G$. parviflora, I S. ori = intercropping with $S$. orientalis, I S. nig = intercropping with $S$. nigrum, I C. cre = intercropping with $C$. crepidioides.

The Content of Cadmium Bound to Carbonates. For the content of $\mathrm{Cd}$ bound to carbonates in soil, compared to monoculture, intercropping with hyperaccumulators all significantly reduced the $\mathrm{Cd}$ bound to carbonates content in soil $(P<0.05)$. And the order of $\mathrm{Cd}$ bound to carbonates content from large to small was ranked: Monoculture, intercropping with $C$. crepidioides, intercropping with S. nigrum, intercropping with G. parviflora, intercropping with S. orientalis (Figure 2). 
The Content of Cadmium Bound to Fe-Mn Oxides. For the content of Cd bound to Fe-Mn oxides in soil, compared to monoculture, only intercropping with G. parviflora and intercropping with S. nigrum significantly increased the content of Cd bound to Fe-Mn in soil (Figure 3). Other treatments all had no significant effects on the Cd bound to Fe-Mn oxides content $(P>0.05)$.

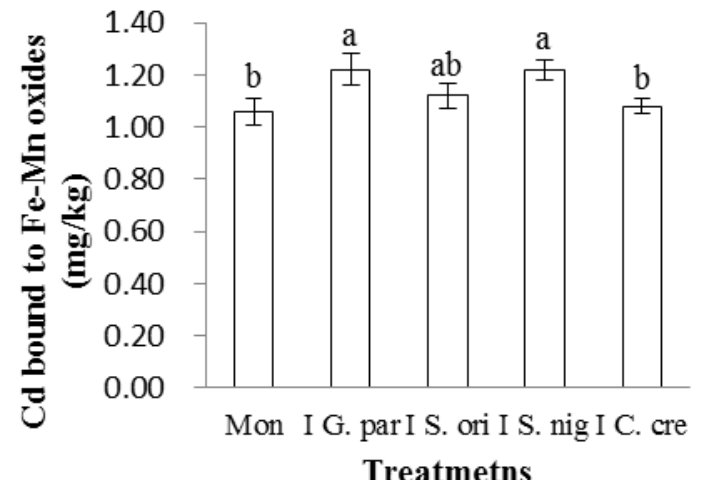

Fig. 3 The content of $\mathrm{Cd}$ bound to Fe-Mn oxides in soil. Different lowercase letters indicate significant differences based on one-way analysis of variance in SPSS 17.0 followed by the least significant difference test $(p<0.05) . \mathrm{M}=$ monoculture, $\mathrm{I} \mathrm{G} \cdot \mathrm{par}=$ intercropping with $G$. parviflora, I S. ori $=$ intercropping with $S$. orientalis, I S. nig = intercropping with $S$. nigrum, I C. cre = intercropping with $C$. crepidioides.

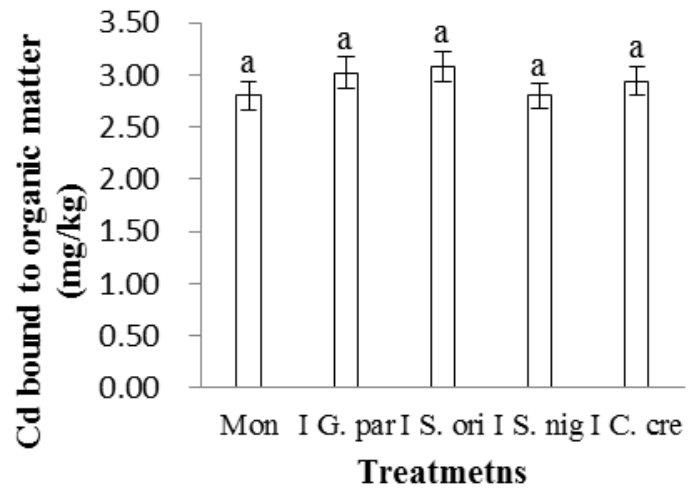

Fig. 4 The content of $\mathrm{Cd}$ bound to organic matter in soil. Different lowercase letters indicate significant differences based on one-way analysis of variance in SPSS 17.0 followed by the least significant difference test $(p<0.05) . \mathrm{M}=$ monoculture, $\mathrm{I} \mathrm{G}$. par $=$ intercropping with $G$. parviflora, I S. ori $=$ intercropping with $S$. orientalis, I S. nig = intercropping with $S$. nigrum, I C. cre = intercropping with $C$. crepidioides.

The Content of Cadmium Bound to Organic Matter. For the content of $\mathrm{Cd}$ bound to organic matter in soil, compared to monoculture, intercropping with hyperaccumulators had no significant effects on Cd bound to organic matter content in soil (Figure 4).

The Content of Residual Cadmium. For the content of residual $\mathrm{Cd}$ in soil, compared to monoculture, only intercropping with $G$. parviflora significantly increased the content of residual $\mathrm{Cd}$ in soil (Figure 5). Other treatments all significantly reduced content of residual $\mathrm{Cd}$ in soil $(P<0.05)$. And the order of residual $\mathrm{Cd}$ content from large to small was ranked: intercropping with G. parviflora, Monoculture, intercropping with $C$. crepidioides, intercropping with $S$. orientalis, intercropping with S. nigrum.

\section{Conclusions}

In the experiment, intercropping with different hyperaccumulators had different effects on the fractions of $\mathrm{Cd}$ in soil. For the content of $\mathrm{Cd}$ bound to organic matter in soil, intercropping with hyperaccumulators had no significant effects on it. And intercropping with hyperaccumulators all significantly reduced the content of Cd bound to carbonates in soil. Compared with monoculture, only intercropping with $S$. orientalis significantly increased the content of exchangeable $\mathrm{Cd}$ in soil. Other treatments had little

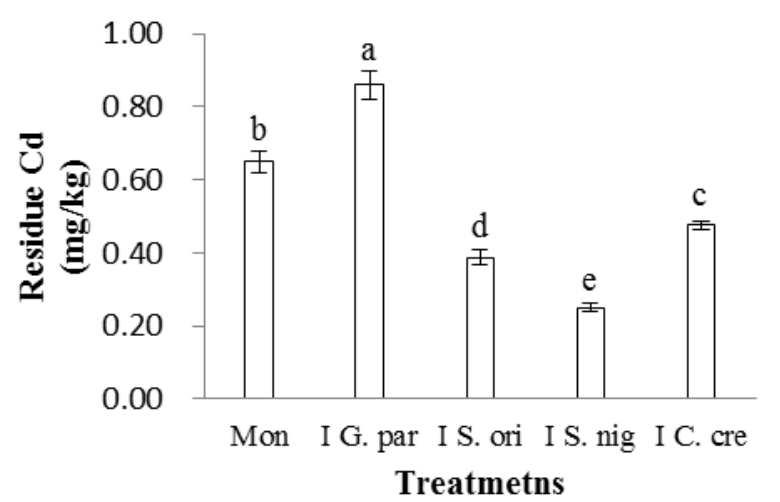

Fig. 5 The content of residual $\mathrm{Cd}$ in soil.Different lowercase letters indicate significant differences based on one-way analysis of variance in SPSS 17.0 followed by the least significant difference test $(p<0.05)$. M $=$ monoculture, I G. par = intercropping with $G$. parviflora, I S. ori = intercropping with $S$. orientalis, I S. nig = intercropping with $S$. crepidioides. nigrum, I C. cre $=$ intercropping with $C$. 
effects on the bioavailability of soil $\mathrm{Cd}$. And only intercropping with $G$. parviflora significantly increased the content of residual $\mathrm{Cd}$, while other treatments significantly reduced its content. In addition, intercropping with $G$. parviflora, intercropping with $S$. orientalis and intercropping with $S$. nigrum increased the content of $\mathrm{Cd}$ bound to $\mathrm{Fe}-\mathrm{Mn}$ oxides in soil to varying degrees. These results indicated that grape seedlings intercropping with $S$. orientalis would significantly increase the bioavailability of soil $\mathrm{Cd}$, which may increase the risk of $\mathrm{Cd}$ uptake by grape seedlings and is not conducive to the safe production of grape. And grape seedlings intercropping with G. parviflora could significantly increase the content of residual $\mathrm{Cd}$, which is conducive to the fixation of $\mathrm{Cd}$ in the soil and may reduce the plant's enrichment of $\mathrm{Cd}$. Therefore, grape seedlings intercropping with G. parviflora could benefit for the decline of bioavailability of Cd.

\section{Acknowledgements}

This work was financially supported by the Application Infrastructure Project of Science and Technology Department of Sichuan Province (2016JY0258).

\section{References}

[1] F.D. Zhan, J.J. Chen, L. Qin, J.X. Wang and Y. Li: Journal of Agro-Environment Science Vol. 35(2016), p. 661.

[2] M.J. Mclaughlin, K.G. Tiller and M.K. Smart: Australian Journal of Soil Research Vol. 35(1997), p. 183.

[3] A. Tessier, P.G.C. Campbell and M. Bisson: Analytical Chemistry Vol. 51(1979), p. 844.

[4] Y.J. Chen, S. Tao and B.S. Deng: Acta Pedologica Sinica Vol. 38(2001), p. 54.

[5] J.J. Chen, H. Xiu and Y. Li: Environmental Science and Technology Vol. 39(2016), p. 63.

[6] T. Liu, L. Ma and N.S. Du: Chinese Journal of Nature Vol. 24(2002), p. 81.

[7] Q. Jin: Study on Antioxidant Enzyme Activity and Photosynthetic Characteristics of Cd-Hyperaccumulator Galinsoga parviflora (Sichuan Agricultural University 2014).

[8] S.R. Zhang, H.C. Lin, L.J. Deng, G.S. Gong, Y.X. Jia, X.X. Xu, T. Li, Y. Li and H. Chen: Ecological Engineering Vol. 51(2013), p. 133.

[9] J. Xu, J. Sun, L. Du and X. Liu: The New Phytologist Vol. 196(2012), p. 110.

[10]G.X. Zhu, H.Y. Xiao, Q.J. Guo, Z.Y. Zhang, X. Yang and J. Kong: Environmental Science Vol. 38(2017), p. 3054.

[11] J.C. Ai, N. Li and N. Wang: Journal of Agro-Environment Science Vol. 32(2013), p. 491. 